\title{
HRM Research in Pakistan: Existing Approaches and Future Directions
}

\author{
Qamar Ali * Julia Brandl ${ }^{\dagger}$
}

\begin{abstract}
Many have highlighted the importance of context-based understanding of HRM in developing countries. We take stock of Pakistan-based HRM literature to examine its context-orientation. Based on the typology of Neuman (2000), we divide the literature into three streams-the positivist, the interpretivist, and the critical. Our analysis reveals that the positivist stream endorses the adoption of Western HRM practices in Pakistan without considering its differences from the West, whereas, the critical stream takes a cynical stance towards the very existence and function of HR departments in Pakistan, thereby undermining the importance of any improvements in the prevailing systems. The interpretive stream, on the contrary, studies the role of national cultural context in shaping HRM practices in Pakistan, and provides relatively more promising knowledge for MNCs to craft their strategies in cultures like Pakistan. However, the analysis of existing interpretivist research is entirely based on old assumptions about the context of Pakistan being characterized as highly collectivist and masculine, unconducive for learning and change, and having a strong propensity for submission to authority and power. We suggest that increased attention towards interpretive approach will enhance context-based understanding of HRM in Pakistan, which will consequently be more useful for local organizations as well as MNC subsidiaries operating in the country. Furthermore, we highlight the cultural and political metamorphoses of Pakistan, providing a strong impetus for a fresh look at the core assumptions about the national context, and discuss its implications for studying HRM in Pakistan.
\end{abstract}

Keywords: HRM, Pakistan, contextual embeddedness, research paradigms, MNCs.

\section{Introduction}

Due to enhanced interconnection and interdependence of 'developing' and 'developed' countries, the former are now increasingly becoming the focus of research. Like many other fields of research, human resource management (HRM) is also emerging in developing countries. Many scholars (Nyambegera, Sparrow, \& Daniels, 2000; Pawan \& Debrah, 2001; Budhwar \& Debrah, 2013) have highlighted its significance for these countries. Scholars are particularly emphasizing upon context-based understanding of HRM in developing countries. The twenty first century has seen a plenty of empirical research in this area focusing explicitly on developing economies like India, Pakistan, Bangladesh, Jordan, Egypt and so on (Baddar Al-Husan, Brennan, \& James, 2009; Budhwar \& Mellahi, 2007; Budhwar \& Debrah, 2013).

Pakistan, due to its distinctive and diversified cultural and ethnic profile, large population, nuclear power, strategically important geographical location, eventful social and

\footnotetext{
*Government College University Faisalabad, Lyallpur Business School, Department of Management, Jhang Road, 38000 Faisalabad. E-mail: qamarwaince@gmail.com

${ }^{\dagger}$ University of Innsbruck, Institute of Organization and Learning, Human Resource Management Unit, Universitaetsstrasse 15, A-6020 Innsbruck. E-mail: julia.brandl@uibk.ac.at
} 
political history, and rich institutional and religious context, is an interesting setting for HRM research. A reasonable amount of HRM research has been conducted in Pakistan in the last one and a half decades. However, it is not clear so far that whether or to what extent the results produced by these studies are useful and should the future research continue on existing pattern and agenda? These questions can be dealt with the help of a systematic review of existing literature (Khilji \& Matthews, 2012). Taking stock of existing research is common in the field of HRM across countries (Budhwar \& Mellahi, 2007; Pio, 2007; Zheng \& Lamond, 2009), however, based on our search of databases, no review of HRM research is found in the case of Pakistan. This study endeavours to fill that gap thereby exploring the existing research of HRM in Pakistan and highlighting its missing links. With the help of the content analysis of research articles published in leading journals, this study intends to understand the purpose and approach of existing research, in order to set a more coherent agenda, which is well attuned to recent historical developments, for future HRM research in Pakistan. The study particularly focuses on the contextual embeddedness of existing literature thereby dividing it into different categories.

Every research study follows a particular approach; and the choice of research approach has strong implications for the potential contextual embeddedness of a study. There are a variety of approaches available. Each approach has its unique philosophical assumptions and methodological stances. These assumptions are not made explicit in most of the research reports and sometimes researchers are not even very clear about their research approaches (Neuman, 2000). Using the taxonomy of social science research approaches (Table 1) given by Neuman (2000), this study splits Pakistan based HRM research into three streams-positivist, critical, and interpretivist.

Table 1

Typology of social science research approaches

\begin{tabular}{lllll}
\hline & Ontology & Epistemology & Methodology & Purpose of research \\
\hline $\begin{array}{l}\text { Positivist } \\
\text { science }\end{array}$ & $\begin{array}{l}\text { Social reality exists, in } \\
\text { a stable manner, indepe- } \\
\text { ndent of researcher's } \\
\text { interpretations or } \\
\text { meaning systems }\end{array}$ & $\begin{array}{l}\text { Scientific inquiry should be } \\
\text { based on precise empirical } \\
\text { observations of individual } \\
\text { behaviors }\end{array}$ & $\begin{array}{l}\text { Surveys, } \\
\text { experiments }\end{array}$ & Prediction and control \\
\hline $\begin{array}{l}\text { Interpretivist } \\
\text { social } \\
\text { science }\end{array}$ & $\begin{array}{l}\text { Social reality is const- } \\
\text { ructed in a process of } \\
\text { meaning-giving by social } \\
\text { actors }\end{array}$ & $\begin{array}{l}\text { Scientific inquiry should be } \\
\text { based on direct detailed } \\
\text { observation of people } \\
\text { in natural settings }\end{array}$ & $\begin{array}{l}\text { Ethnography, } \\
\text { grounded theory, } \\
\text { phenomenology }\end{array}$ & Understanding \\
\hline $\begin{array}{l}\text { Critical } \\
\text { social } \\
\text { science }\end{array}$ & $\begin{array}{l}\text { Social reality exists out } \\
\text { there but it is prone to } \\
\text { changes and } \\
\text { transformations }\end{array}$ & $\begin{array}{l}\text { Scientific inquiry should be } \\
\text { based on critical and } \\
\text { reflexive processes that } \\
\text { go deep beneath the } \\
\text { surface to uncover the } \\
\text { real structures }\end{array}$ & $\begin{array}{l}\text { Dialecticism, } \\
\text { reflexive inquiry, } \\
\text { discourse analysis, } \\
\text { action research }\end{array}$ & Emancipation and change \\
\hline
\end{tabular}

Adapted from Neuman (2000)

The first stream of research, embedded in positivist social science, mainly consists of studies measuring the impact of modern HRM practices on employee satisfaction and performance in Pakistan. Most of the research in this cluster is context ignorant and does not provide much useful analysis of HRM in Pakistan which makes this stream of research 
less insightful for local and multinational organizations. The dominant research approach in this stream is hypothetico-deductivism. These studies implicitly, and in some cases explicitly, endorse the implementation of Western HRM practices in Pakistan without taking into consideration its historical, cultural, and contextual differences from the West. Researchers believe in the role of national institutional environment in shaping organizational practices but also assume a transition taking place in value systems which makes the successful implementation of Western HRM practices possible in Pakistan. Moreover, they highlight a policy-practice gap in local organizational culture and suggest that MultiNational Companies (MNCs) should not only rely on the transfer of policy manuals from West to Pakistan but also ensure the practice or implementation of their policies.

The second stream, embedded in critical social science, comprises studies which take a cynical view towards the nature and approach of existing HRM in Pakistan. These studies explicitly challenge the positivist assumptions about organizations as systems of harmony and bring into light the exploitation of workers by means of HR departments as instruments of domination. They highlight the flipside of HRM in Pakistan and expose the biased, value laden and power-driven motives behind the development of HR departments. These studies follow an inductive approach of reasoning and use qualitative techniques and case study methods. However, the implications of these studies for organizations, particularly MNCs, are not very clear. They only take into consideration the family owned and state owned businesses in Pakistan, and do not consider MNC subsidiaries, and other entrepreneurial ventures. Moreover, these studies defy the core existence and purpose of HR departments in Pakistan which undermines the importance of changes and improvements in the existing structures.

The third stream of research, embedded in interpretive social science, includes studies which take the national culture (i.e. culture of Pakistan) as a variable and study its impact on the practices of multinationals. These studies explore the local context in an interpretative fashion and, compared to the other two streams, provide much more relevant knowledge for MNCs to craft their HR strategies in cultures like Pakistan. Similar to critical studies, they have used qualitative methods of data collection and analysis, following an inductive approach of reasoning. Most common approaches, in this stream, are case studies, ethnographic observations, and in-depth interviews. They suggest that the employment structure in Pakistan is embedded in its national cultural context and highlight challenges facing organizations in implementing global best practices due to strong contextual embeddedness of traditional organizational routines. Organizations adopt these globally diffused HRM policies, yet the practice of such policies is not possible in letter and spirit due to traditional local cultural norms. However, the analysis of this stream of studies is primarily based on longstanding assumptions about the culture of Pakistan being characterized as high at Hofstede (1983)'s masculinity, collectivism, power distance, and uncertainty avoidance indexes. We problematize these assumptions on the grounds of recent socio-cultural and political developments in Pakistan, and emphasize upon the imperativeness of a fresh evaluation of the context of Pakistan for future HRM research.

Based on the analysis of existing literature, and a reflection on current developments in the societal structure of Pakistan, this study provides a number of future research options available to HRM researchers in Pakistan. The following section explains how the 
authors went about searching and selecting articles for this review. Subsequent sections describe in detail the state of research in the three streams (including their methodological approaches and their contribution towards informing MNCs about the local context), directions for future HRM research in Pakistan, and the conclusion.

\section{Procedure for Article Search and Selection}

The process of article search and selection included the following steps. First step was to collect a pool of research papers. For this purpose we used Google Scholar search engine. Advanced search settings in Google Scholar offer a good range of options for search criteria, including keyword search from 'title' or 'anywhere in article', 'return articles authored by, 'return articles dated between', and 'return articles published in'. We initially used "Human Resource Management" and "Pakistan" as search keywords to appear anywhere in article and afterwards tried with all individual functional areas like recruitment, selection, training. and other possible alternatives of HRM like personnel management. as keywords one after another. Since, a lot of Pakistan based research is being published in non-refereed online journals, we used Elsevier, Sage, J store, Taylor and Francis, Springer, Emerald, Wiley and other leading publishers as the criteria for 'return articles published in'. HRM is a multi-disciplinary field of research, and studies relating to HRM get published in a wide range of journals (Batt \& Banerjee, 2012), thus, we did not stick only to mainstream human resource management journals. We also left the option of 'return articles dated between' open, considering a low number of Pakistan based HRM research published in good quality journals. We got a pool of 50 articles after first step.

Second step was to short list the article pool returned by Google scholar to keep the relevant articles for analysis. This shortlisting, based on the analyses of abstracts and keywords, resulted in the drop of many articles due to their theoretical foci on some other disciplines like strategic management, marketing, economics, political science. Although, one or more of the key terms were residing in the text of these articles, still they were out of the scope of this study. This shortlisting ended up in a total of 30 articles; including some articles having no abstract or keywords. Third step was to go through the full texts of all 30 articles. In this step we tried to have a deeper idea of overall themes and foci of different papers. This screening of texts resulted in a further exclusion of some articles either due to their lack of empirical orientation or irrelevance for the current study, reducing the total number of articles to 23. Table 2 provides a list of the journals and corresponding number of articles selected from each journal for the final analysis.

\section{Review of HRM Research in Pakistan}

Next step was to explore the pool of articles selected for analysis. We used Nvivo (10) for initial understanding. Word frequency and text search options of Nvivo helped in categorizing the articles and exploring the themes of research. We assigned nodes \& memos to each source (article) to classify them on the basis of, research questions, methodology, 
Table 2

List of journals and number of articles from each journal

\begin{tabular}{lc}
\hline Name of Journal & No. of Articles \\
\hline Asian Journal of Management Cases & 1 \\
Business History & 1 \\
Education, Knowledge and Economy & 1 \\
Employee Relations & 1 \\
Equality, Diversity and Inclusion: An International Journal & 1 \\
Global Journal of Flexible Systems Management & 1 \\
International Business Review & 1 \\
International Journal of Cross Cultural Management & 2 \\
International Journal of Sociology and Social Policy & 1 \\
International Review of Administrative Sciences & 1 \\
Journal of Management Sciences & 1 \\
Pakistan Economic and Social Review & 2 \\
South Asian Journal of Business and Management Cases & 1 \\
The International Journal of Human Resource Management & 7 \\
The Pakistan Development Review & 1 \\
\hline
\end{tabular}

methods, industry, and findings. Subsequent reading and re-reading of all sources, nodes, and memos ended up in mapping of themes and categorization of research (Berelson, 1971; White, 2002). Table 3 provides a summary of Pakistan based HRM research in a chronological order.

The start of twenty first century is generally considered as the start of a new era of research and development in Pakistan. Due to a substantial increase in the annual budget for higher education and research in year 2000 and afterwards, and subsequent establishment of higher education commission (HEC) of Pakistan in 2002, research culture in Pakistan started flourishing in this period. HEC took many future oriented initiatives thereby expediting the processes and outputs of research in Pakistan. Research papers, in different fields of study, from Pakistan, have started appearing in reputed international journals. As a result, publications of Pakistan based HRM research have also substantially increased over the years. However, despite its progress in numbers in last one and a half decades, HRM research in Pakistan still needs a purposeful direction and agenda, which makes it more relevant to the indigenous issues and challenges (Afiouni, Ruel, \& Schuler, 2014; Khilji \& Matthews, 2012).

A major proportion of Pakistan based HRM research deals, in one way or the other, with HR-performance link. It includes studies which either directly measure this link or deal with the concepts such as employee development, management development, human resource satisfaction (HRS), employee satisfaction, organizational commitment, employee motivation, employee turnover. which indirectly measure the impact of HRM on organizational performance. A same proportion of research explores the influence of national cultural factors on the implementation of West-driven HRM practices in Pakistan. This cluster of research includes studies which either measure national cultural influences on multinational subsidiaries operating in Pakistan or measure their influences on the implementation of modern HRM practices in local organizations in Pakistan. A relatively low proportion of research deals with the rhetoric-reality gap of HRM practices in Pakistan. Most of the research in this cluster involves case studies of local organizations in Pakistan. 


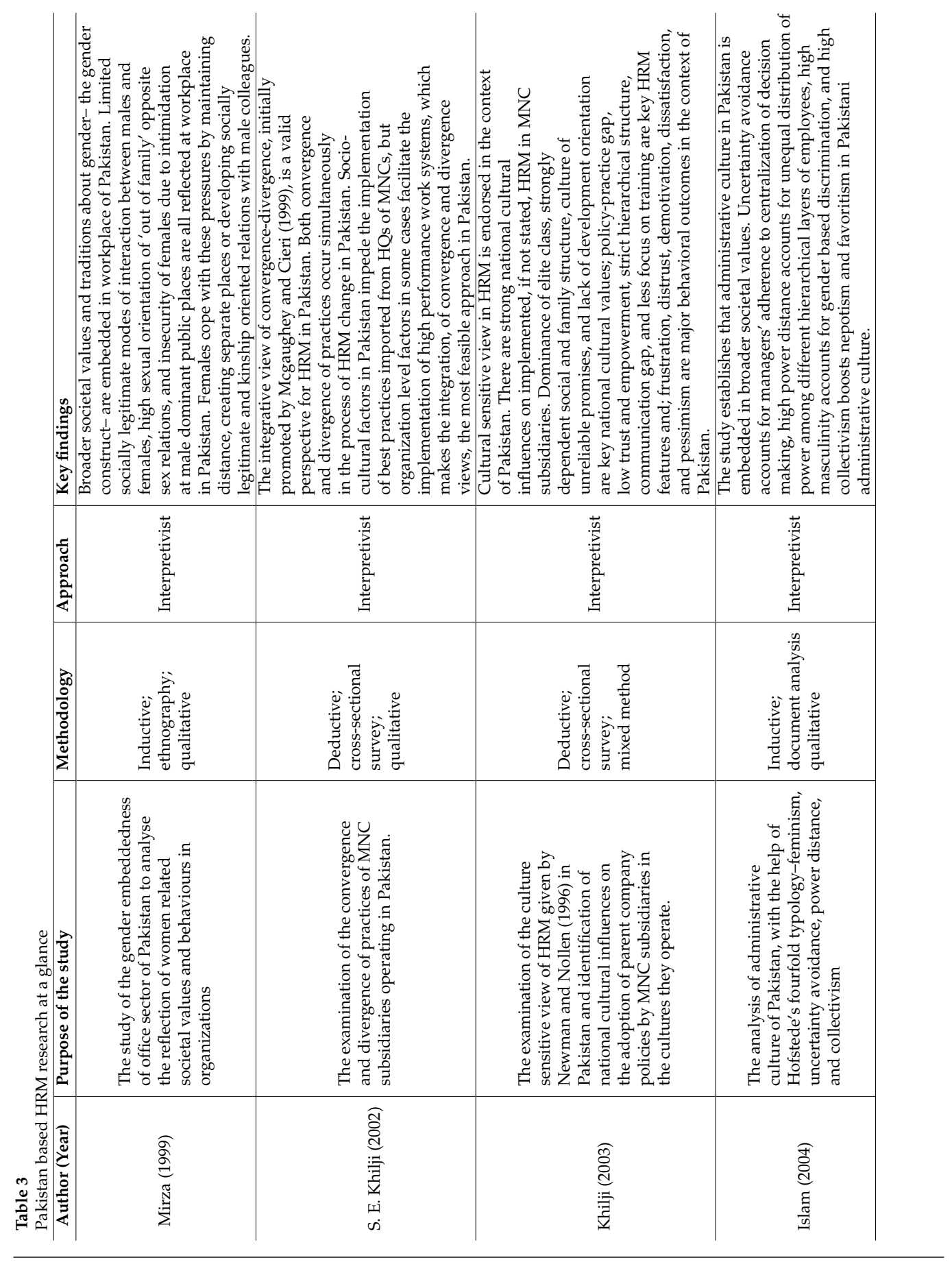




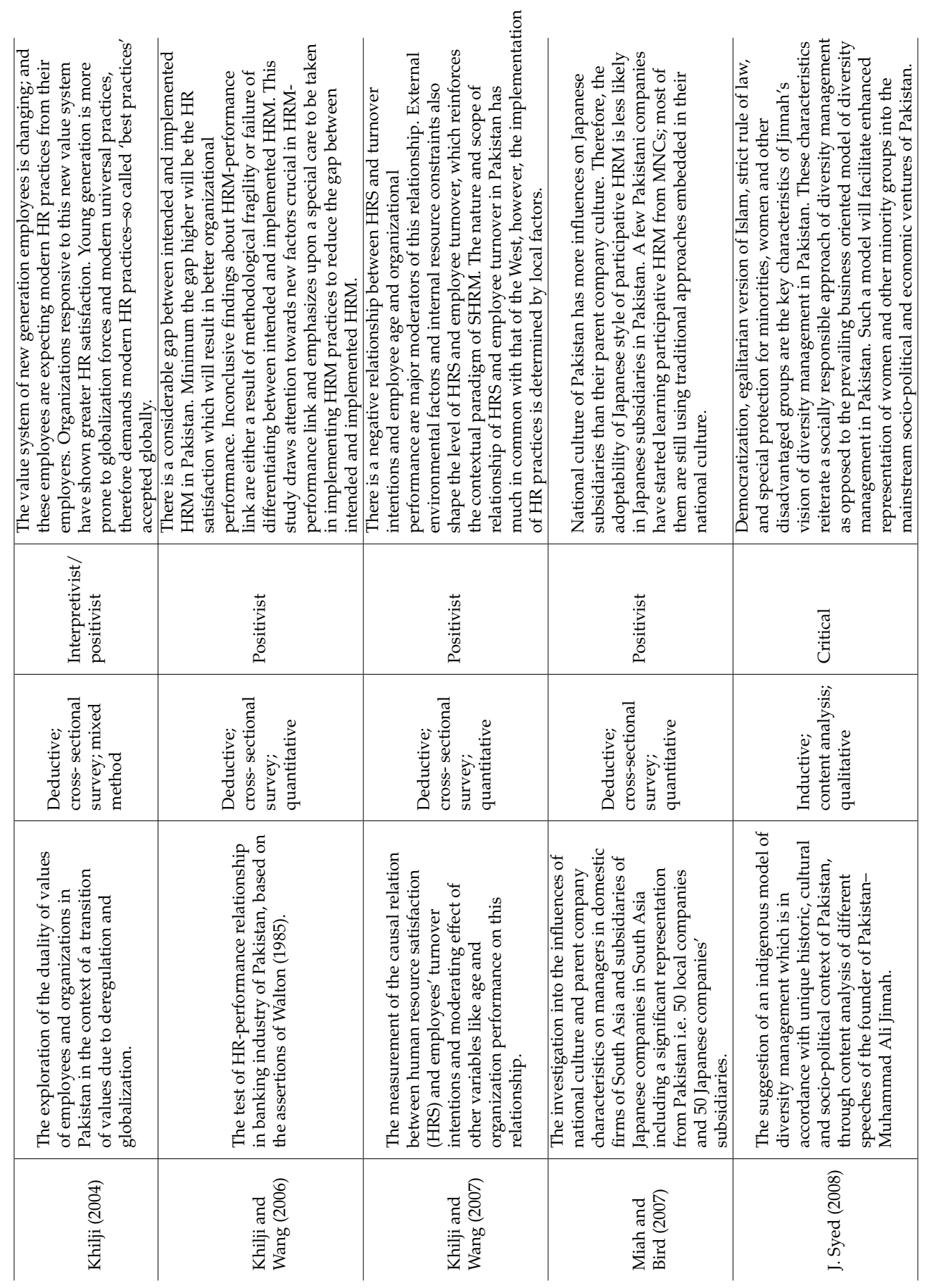




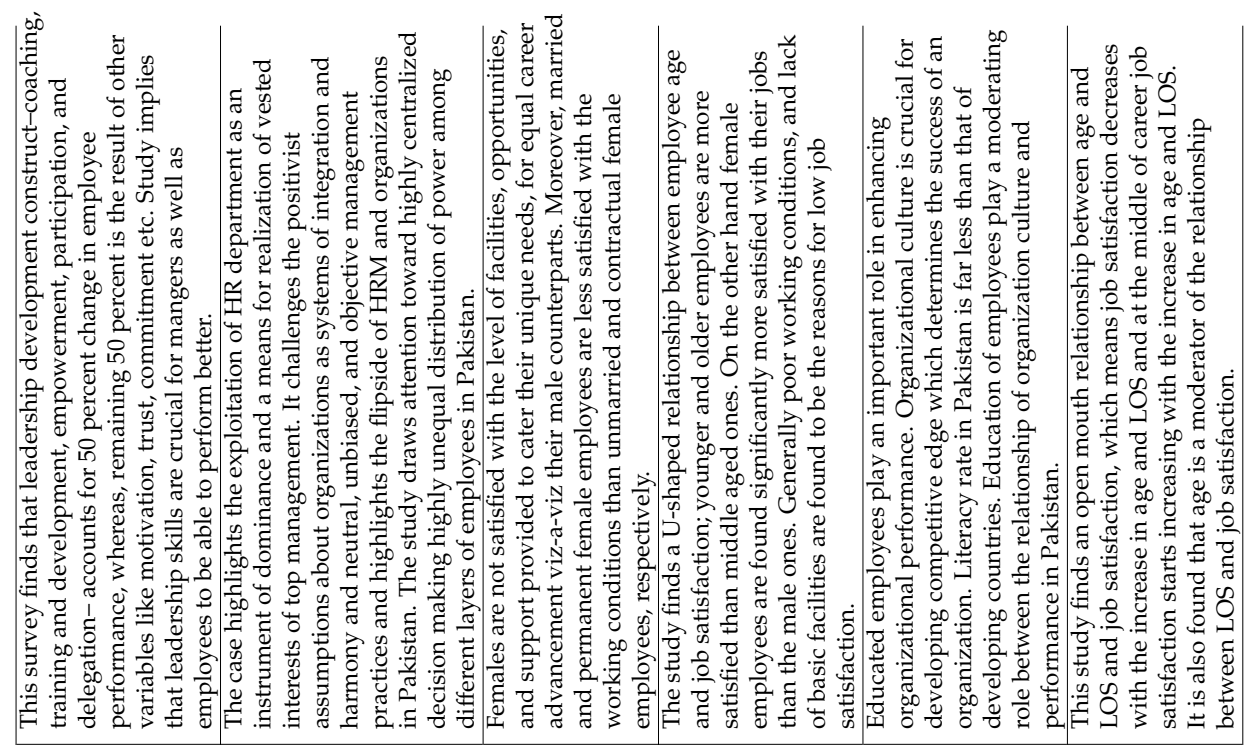

\begin{tabular}{|c|c|c|c|c|c|}
\hline $\begin{array}{l}4 \\
\sum^{n} \\
0 \\
0\end{array}$ & 莺 & 营 & 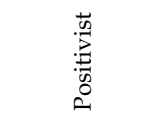 & 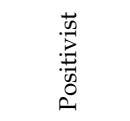 & 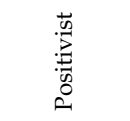 \\
\hline 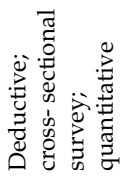 & 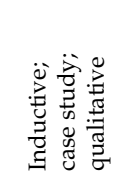 & 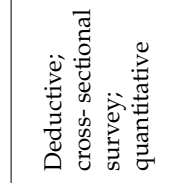 & 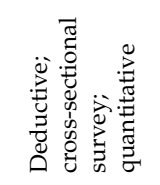 & 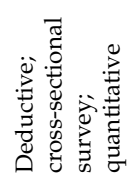 & 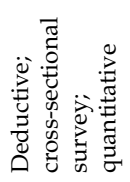 \\
\hline 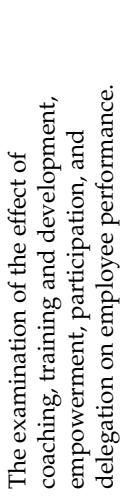 & 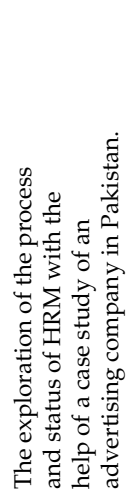 & 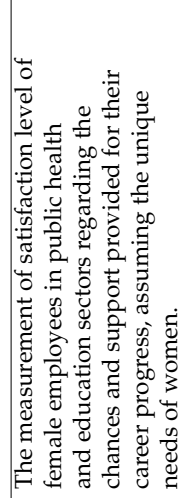 & 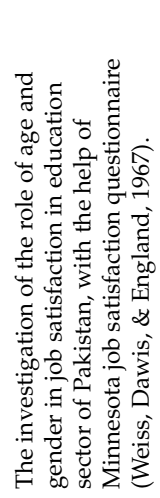 & 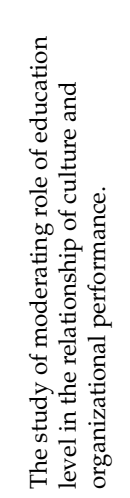 & 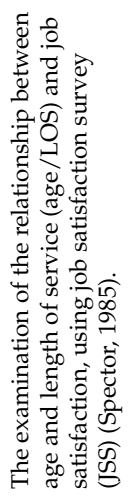 \\
\hline 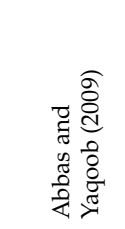 & 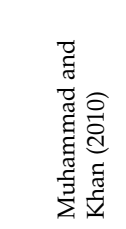 & 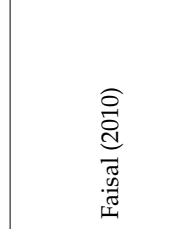 & 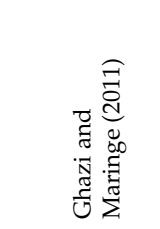 & 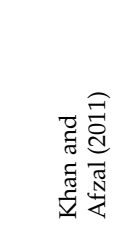 & 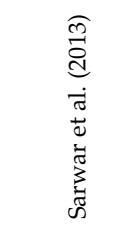 \\
\hline
\end{tabular}




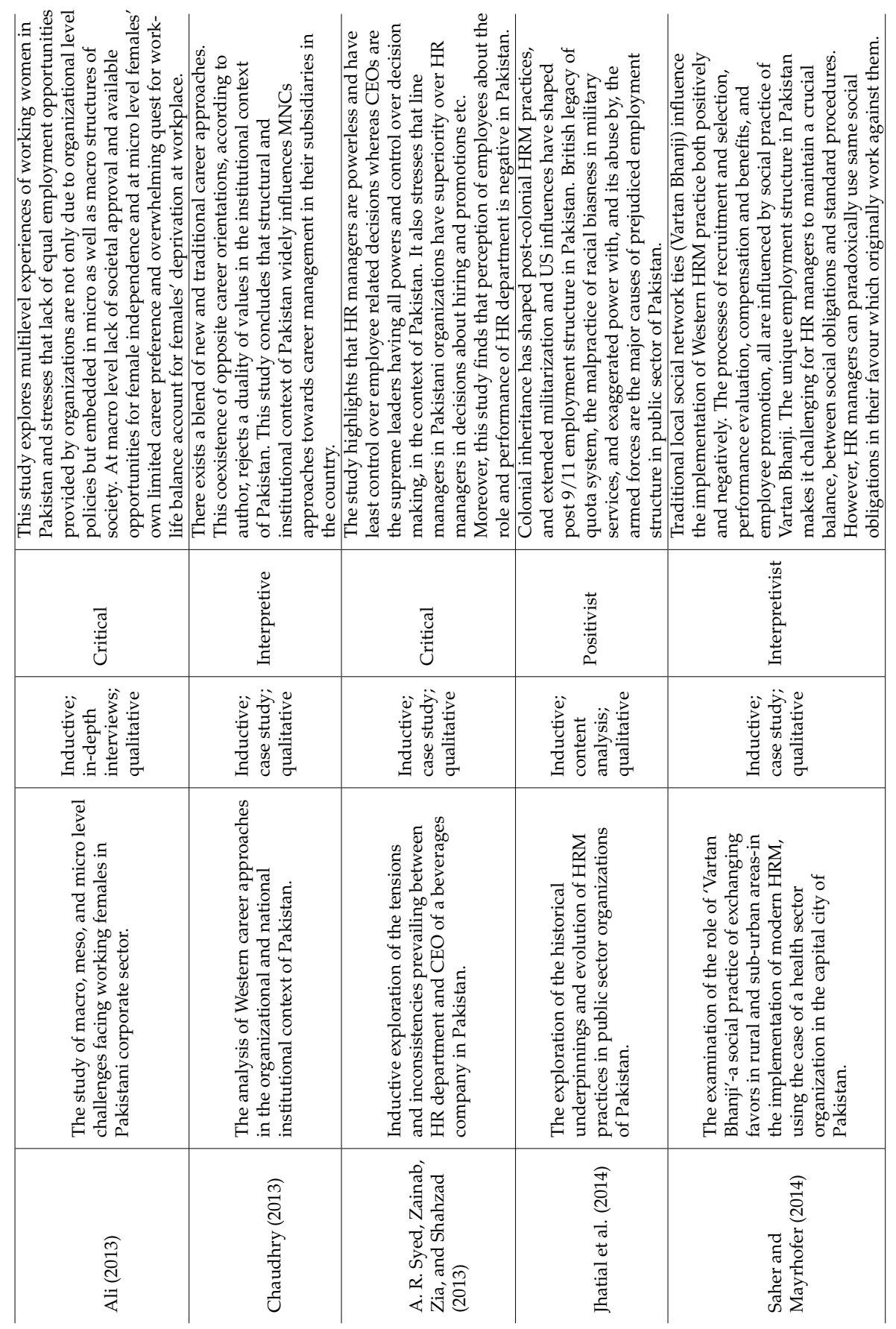




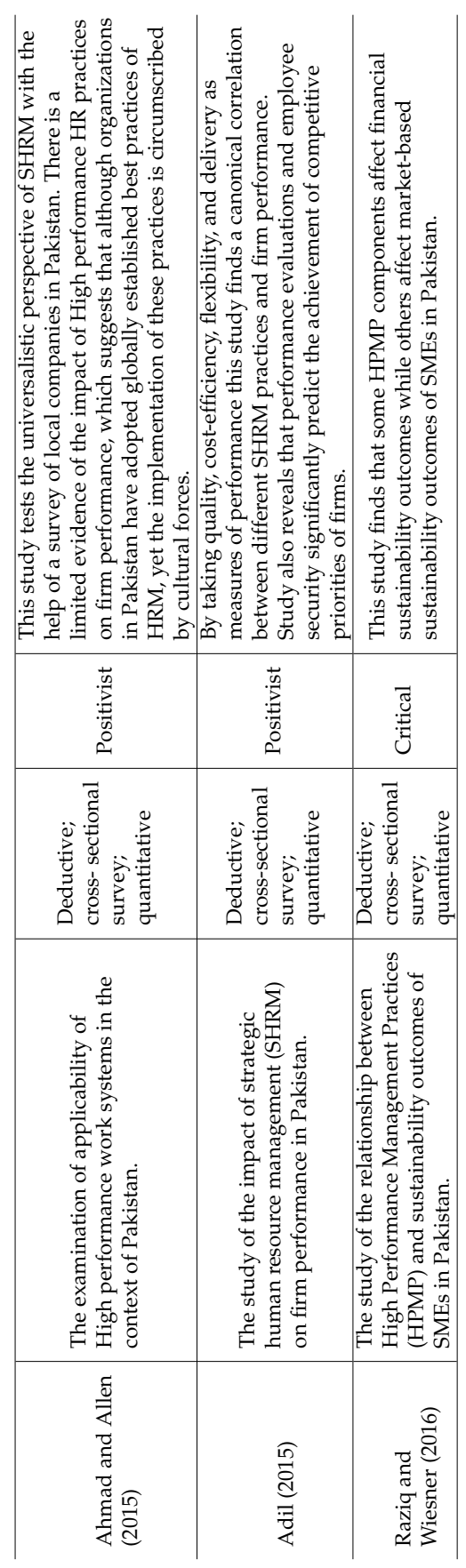


The following section describes, at length, three categories emerged from Pakistan based HRM research and their scope for organizations based on the methodological rigor and contextual embeddedness.

\section{Categorization of Pakistan based HRM research}

After extensive reading, careful review and analysis of nodes and memos attached to each article, and a cognitive mapping of emerging themes, we categorized Pakistan based HRM research into three clusters. The approaches of social science research given by Neuman (2000) worked as the basis for categorization. Different theoretical assumptions and diverse methodological orientations of studies provide the basis of their division into three categories. Research cohort dealing with the HR-performance link is based on positivist approach. Studies, which explore the role of national culture on the implemented of HRM practices in Pakistan, are based on interpretive approach. Whereas, the studies which intend to expose the reality of HRM in Pakistan are found to be based on critical approach. The following is a description of these three cohorts of research.

\section{Modern HRM Practices and Employee Satisfaction in Pakistan: The Positivist Stream}

This stream of research is composed of studies finding the antecedents, determinants, and/or outcomes of employee satisfaction (also termed as job satisfaction and HR satisfaction) in Pakistan. Most of this research intends to measure the impact of age, gender, length of service, gap between stated and implemented HRM practices, duality of values, and high performance work systems on job satisfaction. It measures the organizational outcomes of job satisfaction in the form of employee turnover intentions and organizational performance. These studies are based on cross sectional surveys, use quantitative techniques for data collection and analysis, and adopt pre-established instruments (e.g. job satisfaction survey) for measuring the construct of Job satisfaction. More precisely, this stream of research is embedded in positivist social science, where the studies have mainly used deductive approach of reasoning.

The findings of this stream of research suggest that employee satisfaction is greater in those organizations which are consistent in implementing their intended HRM practices. There are evidences of a substantial gap between stated and implemented HRM practices of both MNCs and local companies in Pakistan. However the intensity of this gap varies among different organizations. Organizations with the lowest gap between intended and implemented practices have shown greater employee satisfaction compared to those where this gap is maximum (Khilji \& Wang, 2006). Intended practices are usually the so-called modern HRM practices (best practices) acknowledged universally. It implies that organizations implementing modern HRM practices achieve greater employee satisfaction in Pakistan. This is also evident in the studies of Abbas and Yaqoob (2009), who find a positive impact of modern leadership development practices on employee performance, and Ahmad and Allen (2015) who find statistical proof for the impact of modern HRM practices on employee related outcomes like absenteeism, labor productivity, and turnover in Pakistani organizations. Similarly, this is also established by Adil (2015), who 
finds a significant impact of strategic human resource management (SHRM) on firm performance, and by Raziq and Wiesner (2016), who find a significant relationship between High Performance Management Practices (HPMP) and sustainability outcomes of SMEs in Pakistan.

There is a blend of traditional societal and modern market oriented norms in work related value system of employees in Pakistan. Young generation, particularly, is going through a transition in work related values shifting from old societal disposition of acceptance and submission to authority, power, and hierarchy to a more market oriented and modern disposition of valuing decentralization and autonomy. Therefore, the younger cohort of employees expect the implementation of modern practices of participative HRM from their employers (Khilji, 2004). But a purely participative HRM is less likely to be implemented in Pakistani organizations because of national cultural influences. Although, a few of Pakistani companies have started learning participative HRM from MNCs, most of them are still using traditional approaches embedded in their national culture (Miah $\&$ Bird, 2007). Organizations more responsive to the young employees' expectations of participative HRM, however, have shown greater employee satisfaction compared to those sticking to the traditional power driven approaches of centralization and command (Khilji, 2004).

Apart from having adopted new set of work related values and looking for a fit of these values with organizational practices, younger employees are, in general, more prone to greater job satisfaction (Sarwar, Mirza, Ehsan, Khan, \& Hanif, 2013). Employee age has a U-shaped relationship with job satisfaction in Pakistan. Young employees are more satisfied with their jobs, as they grow in age they find themselves less and less satisfied unless they reach to the third bracket of age where they again start feeling satisfied with their work. Ghazi and Maringe (2011) reveal similar findings from education sector of Pakistan that employees in younger and older ages tend to be more satisfied from their jobs compared to the middle aged ones. Employee age also moderates the relationship between employee satisfaction and turnover intentions. Younger employees have stronger tendency to quit organization if they are not satisfied from their jobs (Khilji \& Wang, 2007).

Ghazi and Maringe (2011) also measure the relationship of gender and job satisfaction and find that women tend to be more satisfied from their jobs compared to the men. Faisal (2010), on the contrary, reveals that women in public sector of Pakistan are not satisfied from the working environment, facilities provided to them, and chances of career advancement vis-a-vis their men counterparts. The level of dissatisfaction varies among women working in different categories of public sector institutions and with different marital and occupational status. Female employees, however, have less tendency to quit, compared to male employees, in case of dissatisfaction (Khilji \& Wang, 2007).

\section{Rhetoric vs Reality of HRM in Pakistan: The Critical Stream}

Researchers in this stream take a critical stance towards nature and approach of contemporary HR departments and HRM in Pakistan. Most of these studies challenge the positivist assumptions about organizations as systems of integration and harmony and views of neutral, unbiased, and objective management practices and highlight the other side of 
management and organizations in Pakistan. They bring into light the exploitation of HR departments as instruments of dominance and mere means for realization of vested interests of top management. They highlight the biased, value laden and power-driven agenda of organizations and expose the real motives behind the development of HRM departments. These studies, moreover, reveal the structural and political biasness of apparently neutral recommendations of HR managers and expose the helpless and symbolic face of HRM departments which only serve the bureaucratic interests. They mark a blistering criticism on the 'Saith' culture of Pakistan which is prevalent in majority of family-owned businesses in the country.

Findings of this cohort of research reveal the powerlessness of HR departments and helplessness of HR managers in Pakistan. HR departments are used for the fulfilment of vested interests of owners, rather than serve as bridges between employers and employees (Muhammad \& Khan, 2010; A. R. Syed, Zainab, Zia, \& Shahzad, 2013). Authority of decision making is centralized and distribution of power among different layers of employees is highly unequal (Muhammad \& Khan, 2010). Line managers have superiority over HR managers in decisions about hiring and promotions. Perception of employees about the role and performance of HR department is negative (A. R. Syed et al., 2013). Researchers have also found gender and ethnic discrimination in state owned enterprises in Pakistan (Faisal, 2010; Jhatial, Cornelius, \& Wallace, 2014).

Employees are selected on the basis of provincial and regional quota, rather than qualification based open merit. Favouritism and nepotism is common in public sector mainly due to the exaggerated power and influence of military on state institutions. Elite class and retired military generals hold control of key posts at the top of major institutions. British legacy of quota system, the malpractice of racial biasness in military services, and exaggerated power with, and its abuse by, the armed forces are the major causes of prejudiced employment structure in public sector of Pakistan (Jhatial et al., 2014). Working environment is not equally supportive for male and female employees, considering the special needs of the later (Faisal, 2010).

These characteristics of human resource management in Pakistan- favoritism and biasness, unequal opportunities, lack of participation of all groups, and no protective measures for minority groups and females- are in stark contradiction with the values harnessed by the dominant religion (Islam) and advocated by the founder of Pakistan- Muhhammad Ali Jinnah. Jinnah, based on Islamic principles, put forward a vision of democratization, egalitarianism, strict rule of law, and extraordinary measures for minorities, females, and other disadvantaged groups in Pakistan (J. Syed, 2008). The malpractices of nepotism, favoritism, and biased selection, unequal distribution of power, discouragement of participation, and no care for minority groups and females have a place neither in Islamic principles and nor in Jinnah's vision of human resource management in Pakistan. The constitution of Pakistan also prohibits racial and gender discriminations, favoritism and nepotism, and corruption (Ali, 2013). 


\section{Institutional Forces and HRM in Pakistan: The Interpretive Stream}

This stream of research, drawing on broader societal institutions, establishes that employment structure in Pakistan is embedded in its institutional context. Researchers have highlighted challenges facing MNC subsidiaries, and other local organizations, in implementing Modern HRM practices due to strong contextual embeddedness of existing practices. Studies in this stream take into account the unique historic emergence of institutions in Pakistan based on mutually inconsistent sources of inspirations-Indian origin, British colonial legacy, and recent American influences.

Broader societal values, norms, symbols, and rituals are mirrored in organizational practices generally and HRM practices particularly in Pakistan. For instance, Pakistani society's high orientation for collectivism is mirrored in management and HRM practices in the form of nepotism and favoritism (Islam, 2004; Khilji, 2002). High inclination for uncertainty avoidance and acceptance of and submission to authority is reflected in managements' adherence to centralization of decision making, strong hierarchies, and little room for bottom up participation (Khilji, 2003).

Unequal distribution of power among different layers of hierarchy and among different departments is a reflection of high power distance. Unequal treatment with males and females or gender based discrimination is a reflection of high masculine orientation (Islam, 2004). A culture of strong social ties, mutual expectations, and social obligations prevailing in agrarian societies of Pakistan is mirrored in reference based practices of selection, appraisal and promotion and paternalistic management practices (Saher \& Mayrhofer, 2014). Dominance of elite class, strongly dependent social and family structure, culture of unreliable promises, and lack of development orientation in society account for policy-practice gap, low trust and empowerment, strict hierarchical structure, communication gap, and less focus on training as key HRM features, and frustration, distrust, demotivation, dissatisfaction, and pessimism as major behavioral outcomes in organizations (Khilji, 2002). Moreover, mutually opposite career orientations of Pakistani workforce, based on new and traditional career approaches, reflect the duality of values (Khilji, 2004) prevailing in the national cultural (Chaudhry, 2013).

Societal preference of familial relationships over rules and regulations and agrarian traditions of mutual expectations, interdependence, mutual reliance, and exchange of favors account for a distinct employment relationship, based on mutual social expectations, unlike a typical capitalist employment relationship, in Pakistan (Khilji, 2003; Saher \& Mayrhofer, 2014). These societal norms are mirrored in organizations in the form of horizontal and vertical relationships among employees and core and peripheral layers of employee groups depending on strong and weak social bonds among employees.

This distinct employment structure produces a unique setting for HR managers where they have to maintain a crucial balance, between social obligation of returning favors and standard operating procedures, in making decisions about recruitment and selection, performance appraisals, and promotions. Although, MNC subsidiaries adopt their parent company HRM policies, yet the practice of such policies is not possible in letter and spirit due to traditional local cultural norms (Khilji, 2003). HR managers, however, can use the same social network ties, which hinder the implementation of modern HR practices, as a 
force at the back in implementing these practices (Saher \& Mayrhofer, 2014).

Detachment and isolation of female employees from male employees at workplace is a reflection of high sexualization of male-female relationships in the society (Mirza, 1999). Whole female employment structure in Pakistan is embedded in broader societal gender construct and stereotypes. High sexual inclination in opposite gender relations other than kinship or lack of desexualized and socially legitimate modes of interaction between males and females in society limits the number of activities and official roles women can perform at workplace. Incessant sense of insecurity of females in male public spaces, innate in the societal order, entices gender based work organization and space allocation in the office setup (Mirza, 1999). Women modesty and inhibition prevailing in societal practices further aggravate this phenomenon, as women in this society do not feel comfortable expressing the problems and grievances of sexual nature. Societal disapproval of and discontent with females working outside the home and generally expected stereotypical family oriented and household role of females accounts for their lack of professional opportunities and limited career growth in organizations (Ali, 2013).

\section{Discussion on Existing Literature}

The positivist stream of HRM research in Pakistan, based on its methodology and approach, can be attributed as embedded in universalistic paradigm of HRM (see Brewster (1999) for a deeper knowledge about different paradigms in HRM). Some researchers apparently point out the applicability of contextual paradigm in their analysis, but a critical review of their discussions and conclusions reveals that they are also largely influenced by the universalistic assumptions. Most of the studies inform that researchers in other countries have also identified the same antecedents and outcomes of employee satisfaction. These studies strongly endorse that employee satisfaction is a universal phenomenon and HRM practices which enhance employee satisfaction are same all over the world, while ignoring the differences of such relationship in different contexts.

A critical analysis of this stream of research reveals a common pattern of assumptions and analyses where authors are trying to endorse the possibility, viability, and a room for implementation of Western HRM practices in Pakistan despite its historical, cultural, and contextual differences from the West. Although, they assume the impact of national culture on organizational practices in Pakistan but, at the same time, also assume a transition in value system which is creating better chances for implementation of Western HRM practices in Pakistan. Moreover, they highlight a policy-practice gap in local organizational culture and suggest that MNCs should not only rely on the transfer of policy manuals from the West to Pakistan but also ensure the practice or implementation of their policies.

This research cluster implies that organizations should implement modern HRM practices, (globally established best practices) to cater the expectations of younger cohort of employees. Secondly they should look for young candidates while recruiting, as younger employees are generally more prone to satisfaction. This has a very crucial implication in terms of a strong question mark on mid-career employees. Whereas, more interpretative studies on the reasons and institutional mechanism behind low satisfaction of mid-career 
or middle age employees can reveal the true picture and ways to deal with this issue. Third, it implies that female workers are much valuable for MNCs as they have been found more satisfied than their male counterparts in private sector, and also they have less tendencies to quit even in case of dissatisfaction. This is however also problematic without more contextually deep studies about gender mechanism and societal embeddedness.

The studies embedded in critical social science follow the inductive approach of reasoning and use qualitative techniques such as content analysis, archives, and case studies. The main contribution of this cohort of research is that it brings into limelight the other side of management and a rhetoric reality gap of HRM practices in Pakistan. What implications they have for MNC subsidiaries and other local companies in Pakistan is a crucial question for this group of studies, however.

Moreover, these studies only take into consideration the family owned and state owned businesses in Pakistan, and do not consider MNC subsidiaries, and other entrepreneurial ventures. They do not tend to capture the institutional logics and justifications for the prevailing phenomena to help organizations understand the underlying mechanisms of employment relationships in Pakistan. Only Jhatial et al. (2014) take into account the British legacy and military influences in their analysis of employment structure of Pakistan, but theirs' too is primarily based on some fundamental contradictions and differences with specific political regimes in Pakistan. These studies, overall, defy the core existence and purpose of HR departments in Pakistan. This type of fundamental critique does not leave any room for improvements in the existing patterns, however.

Studies embedded in interpretive social science follow a contextual approach of HRM, and assume a stronger role of local institutional context in shaping HRM practices in Pakistan. Most of these studies use qualitative methods of data collection and analysis, following inductive approach of reasoning. Research is based on case studies, ethnographic observations, and in-depth interviews. There are a number of implications for organizations arising from the analyses of these authors. MNC subsidiaries trying to implement best practices of recruitment and selection, promotion, employee involvement and employee career management etc. are likely to face difficult challenges in realizing these practices. For instance, pay for performance, or performance based evaluation, compensation, and promotion is likely to confront with the collectivist and agrarian norms of mutual expectations, exchange of favors, and social network ties. Talent-based approaches of recruitment and selection will confront with socially embedded corruption, nepotism, and favoritism. Modern approaches of employee career management will get across with dual and mutually opposing career orientations of Pakistani youth. Whereas, the assumptions and findings relating to gender construct in Pakistan have strong implications for global quest for gender equality and gender balance at workplace.

The analysis of these studies, however, can be problematized on the ground of fundamental assumptions, about the national culture of Pakistan, embedded in the analyses of these studies. These studies assume that society of Pakistan is highly collectivist and masculine; it does not welcome uncertainty and change; and it has an overwhelming acceptance for and submission to authority and power. However, there is a severe upheaval undergoing in Pakistani society where we see people often on streets to protest for the 
reinforcement of their basic rights. Government of Pakistan is facing serious challenges of long marches, sit-ins, and massive public gatherings protesting against corruption and uncommon and biased policies adopted by ruling parties. Anti-status-quo political parties are getting ever greater public support. These recent trends in society refute the fundamental assumptions embedded in this stream of research and call for a fresh look at the values and preferences of people of Pakistan.

\section{Future Research of HRM in Pakistan: New Challenges and New Agenda}

There are two questions which need to be considered to set a more purposeful future agenda for HRM research in Pakistan. First, what makes a research study interesting, for readers from across the world, when it is conducted in a specific country setting like Pakistan? Second, what is unique in today's Pakistan when it is compared with Pakistan a decade and a half ago? These questions are a useful food for thought for HRM researchers and answers to these questions will construct a direction for future HRM research in Pakistan.

One possible answer to first question could be that Pakistan as a research setting is interesting for international readers due to its unique context. Since, HRM researchers are increasingly arguing that models of HRM established in one context cannot necessarily be generalized to other contexts. Brewster (2007), for example, challenges the universal viability of American model of HR practices and stresses for an indigenous European model of HRM informed by local institutional context. Budhwar and Mellahi (2007) and Budhwar and Debrah (2013) argue for the need of local studies developing countries, particularly in Asia, drawing attention towards the context-bound nature of HR practices in different Asian countries. And, on the other hand, scholars like Drori, Meyer, and Hwang (2006) believe that modern standards and scripts of organizing are increasingly diffusing worldwide. These scripts are adapted with variations to the local contexts. The matrimonial of global scripts and local factors gives rise to a unique organizational form furnished with the characteristics of isomorphism and decoupling. A new form of organization, informed by globally diffusing scripts and standards of rationalization and actor-hood, and mediated by the local context, is sweeping around the globe.

This debate stimulates a number of important research questions for HRM in Pakistan. Whether this new form of organization exists in Pakistan or not? Whether state authorities, family ownerships, and traditional bureaucratic patterns of organizing still hold power? Whether and to what extent education, scientizing, individualism, and globally defined human rights have been able to establish their sanctities in the indigenous culture of Pakistan? To what extent the practices of HRM are based on standards and scripts and to what extent individual actors have possibility to decouple from standard requirements?

Increased interest of international scholars in context based studies makes country specific studies in Pakistan important for not only local but international audience. Therefore, more context oriented HRM studies are of greater value compare to those with a little or no attention towards contextual differences in Pakistan. The choice of research approach has strong consequences for the level of contextual orientation of a study. Studies with a deductive approach of quantitative surveys (i.e. positivist approach) are less 
likely to be embedded deeply in local context and consequently offer much little knowledge of the ground realities. These studies remain less helpful for organizations, particularly for MNC subsidiaries operating or ready to operate in the context of Pakistan, and less informative for international HRM scholars. Whereas, studies which inductively explore the underlying mechanisms behind different HRM routines (Kozica, Kaiser, \& Friesl, 2014), taking into consideration the role of local cultural norms, institutional environments (Powell \& DiMaggio, 2012), and conventions based handling of situations (Eymard-Duvernay, Favereau, Orléan, Salais, \& Thévenot, 2005; Thévenot, 2001) are of greater interest to international audience.

Existing research in interpretive stream, although provides an intelligible account of institutional embeddedness of HRM, the focal point is only the macro structures that influence decision making in organizations. It entirely overlooks the micro processes how actors follow, improvise, or manipulate standards and routines, how objects, artefacts, and technologies available in local situational context impede and/or facilitate the performance of these standards, how standard practices have historically emerged, maintained and / or changed and what are the reasons behind these changes? Moreover, existing studies have not so far focused on studying the processes of rationalization behind different organizational routines. Future research should focus on how, in what form, and to what extent the modern standards and scripts are being adopted in a country like Pakistan which is located at the periphery of global village, and not at the centre. To what extent the thinking of individual and organizational actors is informed and influenced by global standards, scripts, and benchmarks? To what extent it is still dominated by indigenous cultural, political, religious, and legal institutional circumstances?

This challenge of understanding the embeddedness of HRM in local and global contexts can only be taken up by increasing the quantity as well as quality of interpretive research in Pakistan. Researchers are required to inductively discover the meanings and perspectives behind the decisions and actions of organizational actors. Interpretative researchers neither intend to predict, approve, or disapprove any actions and decisions like positivist researchers nor do they intend to undermine the existing value system and emancipate the subjects based on their personal values like critical researchers. A good interpretive HRM researcher, being ideographic and inductive, should provide a detailed story of how HR officials follow, manipulate, and/or change existing organizational standards and routines.

To answer second question, some recent developments in the society and institutions of Pakistan are pertinent to mention. Recent changes in the political and social scenario, successful establishment and smooth functioning of modern public and private sector institutions, abrupt rise in the quantity and quality of higher education, and new era of open and independent electronic and print media are among the developments which have changed the context of today's Pakistan to a larger extent compared to the Pakistan a decade and half ago.

Firstly, recent political scenario of Pakistan has changed to a great degree with the emergence of an anti-status-quo mind-set at street level. Aided heavily by the uncontrollable and non-stop use of social media in Pakistan, this new wave has been successful in changing the societal discourse by established mantra of change. A longstanding despair 
and disappointment prevailing in the society of Pakistan is being shaken off.

Does this new discourse of hope, change, and determinism in the society have any implications for HRM in Pakistan? What challenges an ever more aware and emancipated workforce poses on public and private sector institutions. How the traditional bureaucratic and power driven structure fits with the new demands? These and many other related questions should be considered in future.

Secondly, in last few years some newly established public sector institutions have set an altogether different example by producing highly diligent, honest, and disciplined human resources. Higher Education Commission (HEC), City Traffic Police, Highway Patrolling Police, Motorway Police, Cardiology Centres, and Emergency Service 1122 are among the newly established institutions which do not resemble at all with traditional public sector institutions. Traditional institutions like Punjab and Sindh Police, DHQ Hospitals, Boards of Intermediate and Secondary Education, Pakistan International Airlines (PIA), to name a few, are famous for the stories and scandals of their highly corrupt, undisciplined, and disloyal workforce.

What made these newly established institutions exemplary in terms of their human resource performance? How candidates coming from the same societal context perform different and behave different when they are hired by a different institution? How these institutions have been able to set up and maintain unique and progressive HR cultures when other institutions in the same society have been continuously failing to improve their HR behavior? These questions open up a whole new chapter of HRM research in Pakistan.

Thirdly, during the last one and half decades there have been an abrupt increase in the number of chartered universities in Pakistan which are now producing Masters and PhDs in bulks. Furthermore, HEC has awarded thousands of scholarships for foreign as well as local Masters and doctoral studies, during this period. These developments have changed the entire equation of workforce availability in Pakistan. The quantity and quality of higher education in Pakistan has flourished in leaps and bounds in last few years. There is an ever better in quality and ever greater in numbers pool of candidates available to academia as well as industry.

Finally, the new era of independent electronic and print media supported by social networking sites, along with other societal implications, have huge role in strengthening labor unions in Pakistan. Massive protests and sit-ins by different worker associations for the reinforcement of their rights have been publicized by media in last few years. Lawyers, young doctors and nurses, teachers, employees of PTCL, PIA, and Pakistan Steel Mills have shown up on streets a number of times and most of them have been successful in reinforcing their demands. These workers associations are getting publicized and promoted by media against the will of sitting governments.

These developments have entirely changed the context and structure of employment in Pakistan. New challenges need new wisdom for inquiry and new agenda for research. Old assumptions about the employment structure do not suffice. There is a dire need of a new and fresh look at the value system, priorities, and demands of workers, and managerial assumptions, approaches, and strategies of employers in the context of new resources, challenges, opportunities, and threats. 


\section{Conclusion}

This comprehensive review of existing literature provides a clean picture of current state of HRM research in Pakistan, approaches followed by researchers explicitly or implicitly, and significance and implications of studies for MNC subsidiaries and other local organizations in private and public sectors of Pakistan. The study divides existing literature into three streams, based on typology of social science research approaches given by Neuman (2000). Positivist stream of HRM research does not give much attention to the challenge and need of context driven understanding. Critical stream has taken a cynical view towards the core existence and function of HRM department in Pakistan which leads to disappointment about, instead of understanding of, existing phenomena. Increased focus on the 'contextualization' theme can result in a better understanding as to why HRM practices are what they are in Pakistan. This focus towards contextual perspective also requires a shift in methodological approaches. More inductive, instead of deductive, research is required in future. Local processes and practices of HRM can be better explored through case studies and ethnographies instead of survey designs. Studies following interpretative approach have more potential for contextual embeddedness and consequently offer a much better understanding of local institutional logics and conventions.

The study also problematizes the traditional assumptions about the context of Pakistan, based on the ongoing cultural changes in the country. Recent developments in the culture of Pakistan have dramatically changed the HRM context in the country. New challenges require new approaches and fresh agenda for future research. A number of areas for future HRM research have been discussed in the light of current demands of international scholars and recent changes in the political and socio-cultural scenario of Pakistan. 


\section{References}

Abbas, Q., \& Yaqoob, S. (2009). Effect of leadership development on employee performance in Pakistan. Pakistan Economic and Social Review, 47(2), 269-292.

Adil, M. S. (2015). Strategic human resource management practices and competitive priorities of the manufacturing performance in Karachi. Global Journal of Flexible Systems Management, 16(1), 37-61.

Afiouni, F., Ruel, H., \& Schuler, R. (2014). HRM in the middle east: Toward a greater understanding. International Journal of Human Resource Management, 25(2), 133-143.

Ahmad, M., \& Allen, M. (2015). High performance HRM and establishment performance in Pakistan: An empirical analysis. Employee Relations, 37(5), 506-524.

Ali, F. (2013). A multi-level perspective on equal employment opportunity for women in Pakistan. Equality, Diversity and Inclusion: An International Journal, 32(3), 289-309.

Baddar Al-Husan, F. Z., Brennan, R., \& James, P. (2009). Transferring Western HRM practices to developing countries: The case of a privatized utility in Jordan. Personnel Review, 38(2), 104-123.

Batt, R., \& Banerjee, M. (2012). The scope and trajectory of strategic HR research: Evidence from American and British journals. The International Journal of Human Resource Management, 23(9), 1739-1762.

Berelson, B. (1971). Content analysis in communications research. United Kingdom: Hafner Publishers.

Brewster, C. (1999). Strategic human resource management: The value of different paradigms. Germany: Springer.

Brewster, C. (2007). Comparative HRM: European views and perspectives. The International Journal of Human Resource Management, 18(5), 769-787.

Budhwar, P. S., \& Debrah, Y. A. (2013). Human resource management in developing countries. United Kingdom: Routledge.

Budhwar, P. S., \& Mellahi, K. (2007). Introduction: Human resource management in the Middle East. The International Journal of Human Resource Management, 18(1), 2-10.

Chaudhry, S. (2013). Managerial career development in a developing host-country context: A study of American multinationals in Pakistan. The International Journal of Human Resource Management, 24(3), 558-578.

Drori, G. S., Meyer, J. W., \& Hwang, H. (2006). Globalization and organization: World society and organizational change. Oxford University Press.

Eymard-Duvernay, F., Favereau, O., Orléan, A., Salais, R., \& Thévenot, L. (2005). Pluralist integration in the economic and social sciences: The economy of conventions. PostAutistic Economics Review, 34(30), 22-40.

Faisal, F. (2010). Measuring perceptions of work environment among educated female public servants in Pakistan. Pakistan Economic and Social Review, 48(1), 135-165.

Ghazi, S. R., \& Maringe, F. (2011). Age, gender and job satisfaction among elementary school head teachers in Pakistan. Education, Knowledge and Economy, 5(1-2), 17-27.

Hofstede, G. (1983). National cultures in four dimensions: A research-based theory of cultural differences among nations. International Studies of Management E Organization, 13(1-2), 46-74. 
Islam, N. (2004). Sifarish, sycophants, power and collectivism: Administrative culture in Pakistan. International Review of Administrative Sciences, 70(2), 311-330.

Jhatial, A. A., Cornelius, N., \& Wallace, J. (2014). Rhetorics and realities of management practices in Pakistan: Colonial, post-colonial and post-9/11 influences. Business History, 56(3), 456-484.

Khilji, S. E. (2002). Modes of convergence and divergence: An integrative view of multinational practices in Pakistan. International Journal of Human Resource Management, 13(2), 232-253.

Khilji, S. E. (2003). To adapt or not to adapt' exploring the role of national culture in HRM- A Study of Pakistan. International Journal of Cross Cultural Management, 3(1), 109-132.

Khilji, S. E. (2004). Whither tradition? Evidence of generational differences in HR satisfaction from Pakistan. International Journal of Cross Cultural Management, 4(2), 141-156.

Khilji, S. E., \& Matthews, C. D. (2012). Editor's perspective: Published south asian research: current standing and future directions. South Asian Journal of Global Business Research, 1(2), 154-176.

Khilji, S. E., \& Wang, X. (2006). 'Intended' and 'implemented' HRM: The missing linchpin in strategic human resource management research. The International Journal of Human Resource Management, 17(7), 1171-1189.

Khilji, S. E., \& Wang, X. (2007). New evidence in an old debate: Investigating the relationship between HR satisfaction and turnover. International Business Review, 16(3), 377-395.

Kozica, A., Kaiser, S., \& Friesl, M. (2014). Organizational routines: Conventions as a source of change and stability. Schmalenbach Business Review: ZFBF, 66(3), 1-30.

Miah, M. K., \& Bird, A. (2007). The impact of culture on HRM styles and firm performance: Evidence from Japanese parents, Japanese subsidiaries/joint ventures and South Asian local companies. The International Journal of Human Resource Management, 18(5), 908-923.

Mirza, J. (1999). Accommodating "purdah" to the workplace: Gender relations in the office sector in Pakistan. The Pakistan Development Review, 38(2), 187-206.

Muhammad, F., \& Khan, F. R. (2010). HRM at Affluent Advertising (Pvt.) Ltd. Asian Journal of Management Cases, 7(2), 177-198.

Neuman, W. L. (2000). Social research methods: Qualitative and quantitative approaches. Boston: Allyn and Bacon.

Nyambegera, S. M., Sparrow, P., \& Daniels, K. (2000). The impact of cultural value orientations on individual HRM preferences in developing countries: Lessons from Kenyan organizations. International Journal of Human Resource Management, 11(4), 639-663.

Pawan, S. B., \& Debrah, Y. A. (2001). Human resource management in developing countries. United Kingdom: Routledge.

Pio, E. (2007). HRM and Indian epistemologies: A review and avenues for future research. Human Resource Management Review, 17(3), 319-335.

Powell, W. W., \& DiMaggio, P. J. (2012). The new institutionalism in organizational analysis. University of Chicago Press. 
Raziq, A., \& Wiesner, R. (2016). High performance management practices and sustainability of SMEs. Evidence from manufacturing and services-based industries in Pakistan. Journal of Management Sciences, 3(2), 83-107.

Saher, N., \& Mayrhofer, W. (2014). The role of Vartan Bhanji in implementing HRM practices in Pakistan. The International Journal of Human Resource Management, 25(13), 1881-1903.

Sarwar, S. Z., Mirza, E., Ehsan, N., Khan, K., \& Hanif, H. (2013). Determining the impact of age and LOS on job satisfaction: A case study of Pakistan automotive industry. The International Journal of Human Resource Management, 24(2), 415-435.

Syed, A. R., Zainab, A., Zia, S. A., \& Shahzad, K. (2013). Pakistan foods and beverage company. South Asian Journal of Business and Management Cases, 2(2), 151-162.

Syed, J. (2008). Pakistani model of diversity management: Rediscovering Jinnah's vision. International Journal of Sociology and Social Policy, 28(3/4), 100-113.

Thévenot, L. (2001). Organized complexity: Conventions of coordination and the composition of economic arrangements. European Journal of Social Theory, 4(4), 405-425.

White, H. (2002). The historical text as literary artifact. Narrative Dynamics: Essays on Time, Plot, Closure, and Frames, 191-210.

Zheng, C., \& Lamond, D. (2009). A critical review of human resource management studies (1978-2007) in the People's Republic of China. The International Journal of Human Resource Management, 20(11), 2194-2227. 